\title{
„Hervorragender Ablauf, gute Gespräche“
}

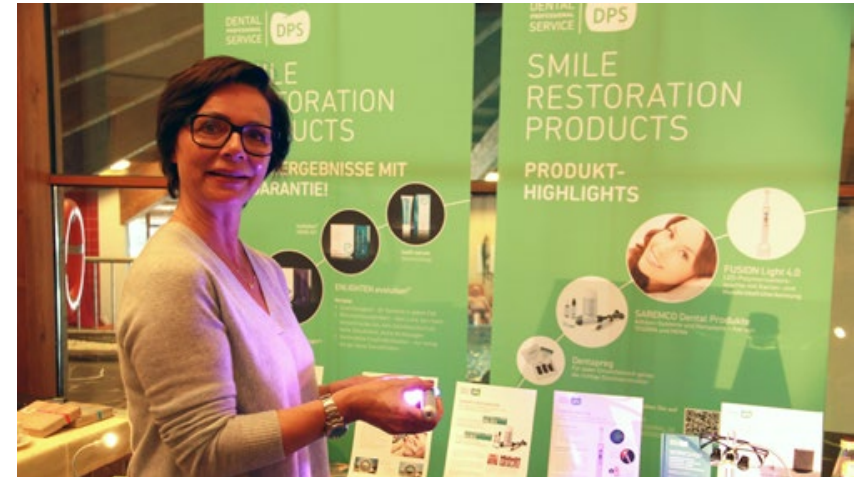

Petra Oberscheid, Fa. DPS:

„Es ist schön, dass wir am Winterkongress ausstellen können und viel Zeit für individuelle Beratungsgespräche mit den Teilnehmern haben."

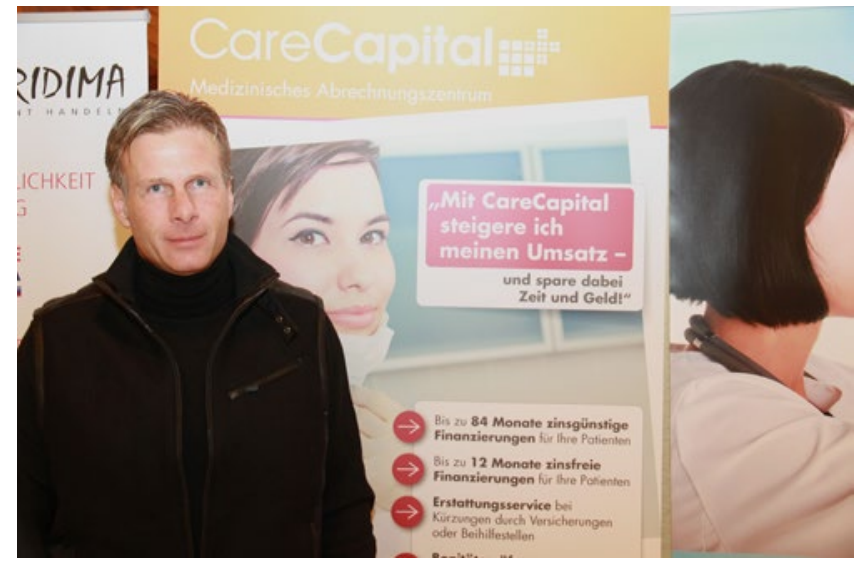

Michael Clement, Fa. Care Capital:

„Wir sind dankbar für die Teilnahmemöglichkeit hier. Hervorragender Ablauf, super Vorträge, rundum gute Gespräche - das zeichnet den Winterkongress aus."

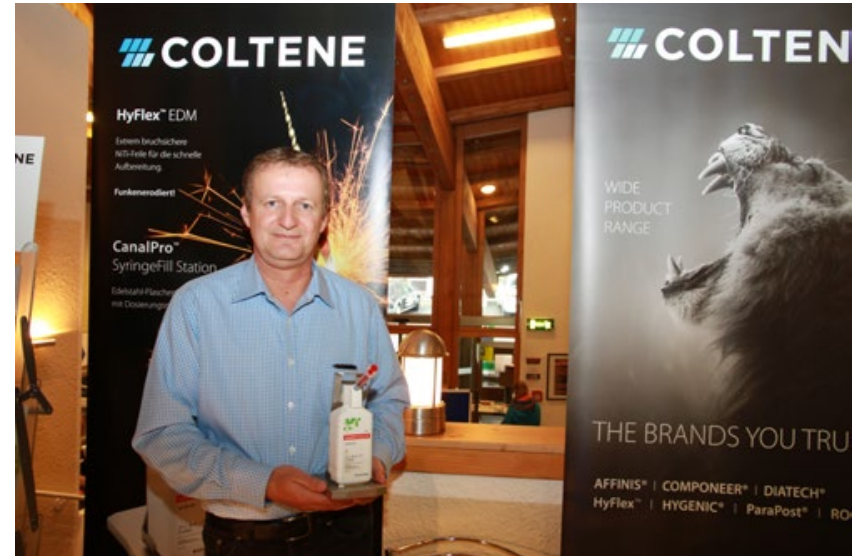

Andreas Schmädicke, Fa. Coltène/Whaledent GmbH \& Co. KG: „Die Organisation ist gut, das Interesse könnte besser sein, aber erfahrungsgemäß wächst das mit dem Verlauf des Kongresses."

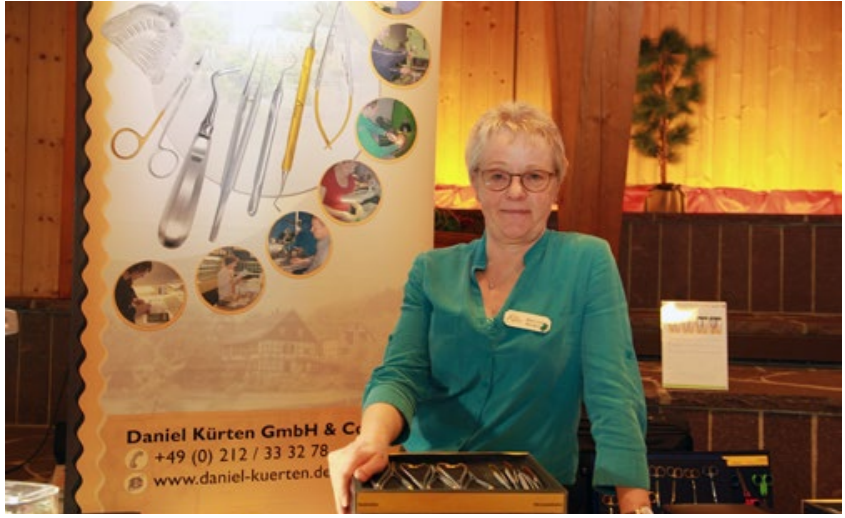

Martina Berkel, Fa. Daniel Kürten GmbH \& Co KG:

"Ein schöner Kongressort, wir wohnen wunderschön in Ischgl Mathon."

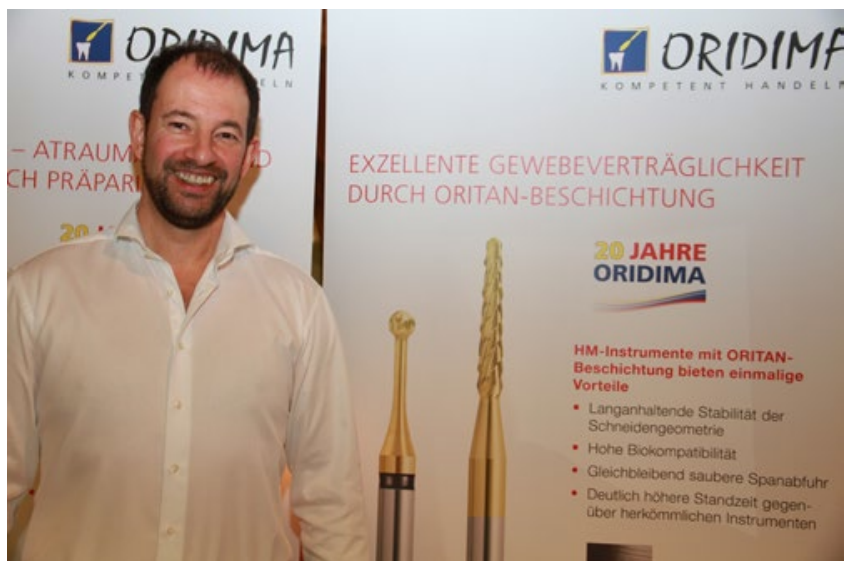

Thomas Speith, Fa. Oridima Dentalinstrumente GmbH \& Co. KG: „Wir stellen schon seit etlichen Jahren beim Kongress des Freien Verbandes aus. Es läuft alles reibungslos, wir sind sehr zufrieden."

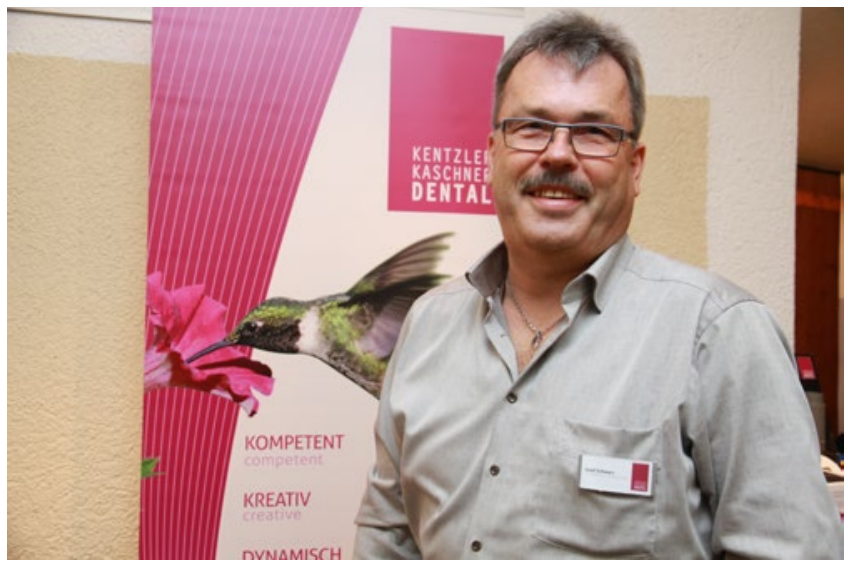

Josef Schwarz, Fa. Kentzler-Kaschner Dental GmbH:

„Wir stellen seit 46 Jahren beim FVDZ aus, ich selbst bin seit 33 Jahren schon dabei. Der FVDZ ist ein wichtiger Partner für uns." 